\title{
Verspäteter Fortbildungsnachweis senkt das Honorar
}

\author{
Ärzte sollten den Kalender im Blick behalten: Denn selbst wenn sie ihre \\ 250 Fortbildungspunkte erreicht haben, kann die KV den Rotstift ansetzen \\ - nämlich dann, wenn der Nachweis zu spät eingereicht wird.
}

Geht es um die Fortbildungspflicht von Vertragsärzten, drücken nicht nur die KVen, sondern auch die Gerichte kein Auge zu: Wie das Sozialgericht (SG) Marburg entschied, muss die KV einem Arzt auch dann das Honorar kürzen, wenn er es lediglich versäumt hat, rechtzeitig gegenüber der KV seine Fortbildungen nachzuweisen. Ob er diese tatsächlich innerhalb des gesetzlich vorgegebenen Fünf-Jahres-Zeitraumes absolviert hat, sei nicht entscheidend.

Im verhandelten Fall wurde einer orthopädischen Gemeinschaftspraxis mit zwei Fachärzten das Honorar für die Quartale III und IV 2009 um insgesamt 11.473,11 Euro gekürzt. Einer der beiden Ärzte hatte nicht rechtzeitig zum Stichtag 30. Juni 2009 belegt, dass er über seine 250 Fortbildungspunkte verfügte.

Allerdings wurde die Honorarkürzung laut KV auf den säumigen Arzt herunter gerechnet. Dagegen klagte die Praxis.

Der Arzt habe im maßgeblichen Zeitraum seine Fortbildungspflichten erfüllt. Es liege kein Säumnis hinsichtlich der Fortbildung vor, sondern lediglich ein Säumnis hinsichtlich des Nachweises.

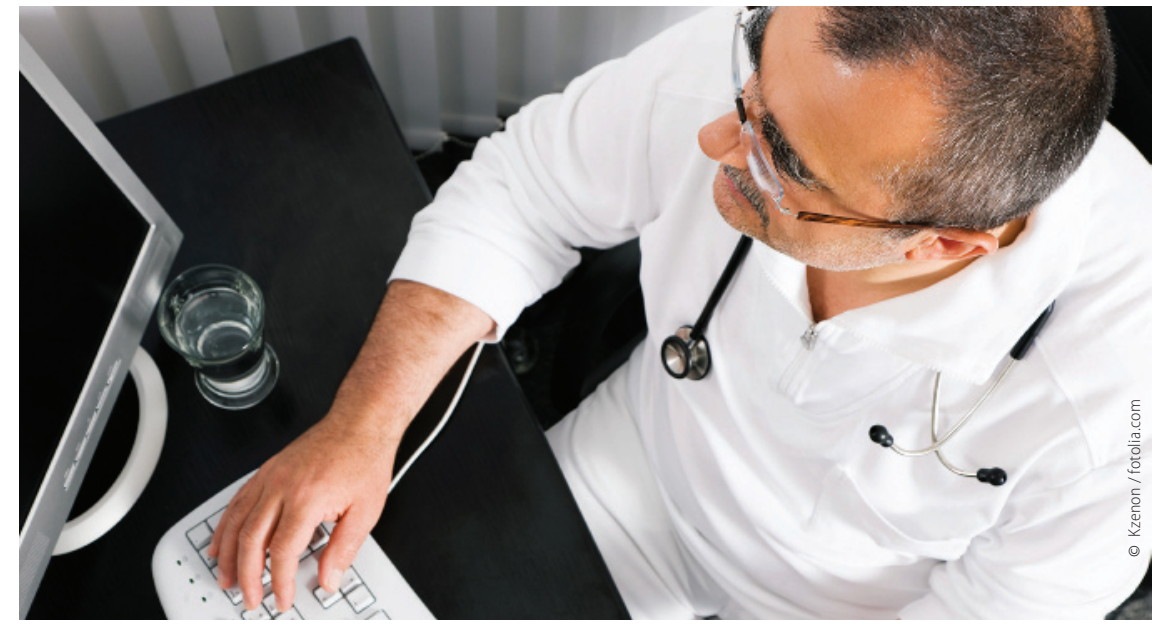

Und auch die Landesärztekammer Hessen bestätigte, dass der betroffene Arzt bis zum 30.6.2009 sogar mehr als 250 Punkte erreicht hatte. Der Nachweis darüber sei allerdings erst am 6. November 2009 bei der Kammer erfolgt.

Und genau das ist das Problem. Wie das Sozialgericht klarstellte, stelle die gesetzliche Regelung deutlich auf den Nachweis und eben nicht nur auf die Erfüllung der Fortbildungspflicht ab.
Da es sich bei der Stichtagsregelung in Paragraf 95d SGB V außerdem um eine Ausschlussfrist handele, sei

eine Wiedereinsetzung in den vorherigen Stand ausgeschlossen.

Die Praxis konnte - so die Richter auch nicht belegen, dass sie die Nachweisfrist ohne eigenes Verschulden versäumt hatte.

(Rebekka Höhl)

Ärzte Zeitung, 17.05.2012

\section{Haut-Dossiers auf springermedizin.de}

Aktuelle Fortbildungsbeiträge, Kasuistiken, Studien und Kongresshighlights zu den Themen Akne, Vitiligo, Botulinumtoxin, Hautalterung oder Warzen finden Sie in den entsprechenden Dossiers auf springermedizin.de.

Im Dossier Warzen haben wir u. a. für Sie zusammengestellt:

- Erfolgsrezept gegen Warzen.
- Globuli gegen Warzen, Pilze, Dermatitis? Davon hat die Haut nichts.

- Was hilft besser gegen Dornwarzen - Salicylsäure oder vereisen?

- Abwarten oder wegätzen? Punkten Sie mit Kinderwarzen!

- Noch immer ein Tabuthema: Bei Genitalwarzen den Ping-Pong-Effekt stoppen!
Das Dossier finden Sie unter -www.springermedizin.de/2277634

oder indem Sie auf der Startseite www.springermedizin.de die Nummer $>2277634$ in das Suchfeld eingeben.

- Auf der Startseite von springermedizin.de stehen Ihnen im Portlet „Dossiers" zahlreiche weitere Themenzusammenstellungen zur Verfügung. 